\section{MOSQUITOES AND MAN}

A UNIQUe deduction, and one likely to be of great value to sanitarians has been reached as one of the results of the work done in the Canal Zone by Major P. M. Ashburn, Medical Corps, U. S. Army. As general inspector, health department, Canal Zone, Major Ashburn became intimately acquainted with the breeding conditions there, and one result of his observation may be summed up in his statement "the malarial mosquito follows man." This means also that their breeding places are normally within convenient reach of human habitation and becomes a very effective as well as an entirely new viewpoint of already recognized conditions, and a viewpoint it would be wise to keep in mind wherever health, effciency and mosquito control are to be considered.

Major Ashburn in referring to the wellproven flight of anophelines of "more than a mile from their place of breeding" draws attention to the facts ${ }^{1}$ that there is at this particular location " a large area where the conditions for breeding are unusually favorable ... an enormous amount of breeding . . . lack of abundant human blood for food in the neighborhood of the breeding place, the presence of abundance of food (a town) at a distance of a mile," and goes on to say "were there another town within two hundred yards or a quarter or half of a mile, the chances are that the town a mile away would scarcely notice any change in the number of mosquitoes." "In fact such has been the experience at several places on the Isthmus," and, referring to another location adds: "The conditions favored a big flight, but a human barrier in the neighborhood served to check it and make the increase of mosquitoes merely a local one."

In another paper ${ }^{2}$ Major Ashburn speaks of

1 Ashburn, P. M., Major, Medical Corps, U. S. A., "Elements of Military Hygiene," 2d ed. (1915), pp. 285.

2 Ashburn, P. M., Major, Medical Corps, U. S. A., general inspector, health department, Panama Canal, "Some Observations Bearing on the Control of Malaria.', Read before the Canal Zone Medical Association, late in 1914. the conditions in the Canal Zone where places that had been "great hot beds of malaria, and great breeding places for Anopheles albimanus, now, since their depopulation, have very few or no Anopheles" mentioning the water works at Miraflores, Cocoli, Ancon Village as examples and refers to a few instances where Anopheles which "were supposed to have come from considerable distances, the situations were found controllable by intensive effort expended close at hand," while the hydraulic fills at several places which gave rise to much increased breeding did not give rise to flights of great length, because "there was food nearer at hand."

Naturally the interposition of "an animal barrier between extensive Anopheles breeding places and human habitation" was considered, but this was found to have already been proven of small or no value.

Major Ashburn then evolved an hypothesis including " $(A)$ Parasitism, (B) Long Flights, (C) Anopheles breeding far from man not malarial carriers." It is with the last point we are most concerned, although, of course, the three parts are really interdependent.

Major Ashburn calls attention to the fact that Anopheles apicimaculatus, not a malaria carrier, was often found breeding 800 yards from human habitation, and that even a temporary construction camp of a large gang of negroes was enough to bring malaria carriers to a given place, and the removal of the laborers was followed by a discontinuance of the breeding of malaria carriers at that place.

Finally, at a contractor's camp, established November 26, 1913, at Caño Saddle, in a previously uninhabited location, hand catching of mosquitoes showed an increase in the weekly takings of malaria carriers as indicated in the following partial table:

\begin{tabular}{|c|c|}
\hline Week Ending & Malaria Carriers \\
\hline December 6, 1913 & 6 \\
\hline December 13, 1913 & 34 \\
\hline December 20, 1913 & 165 \\
\hline December 27, 1913 & 115 \\
\hline January 31, 1914 & . 1,211 \\
\hline March $7,1914 \ldots$ & . . 3,277 \\
\hline May 9, 1914 & 87 \\
\hline
\end{tabular}


After which, at the approach of the dry season, and the discontinuance of the camp early in 'May the numbers gradually lessened.

So far as the incidental appearance of malaria is concerned, while Major Ashburn says the reports are perhaps unduly favorable, the first case was sent into hospital February 7. In December, shortly after the opening of the camp it was inspected and malaria was predicted, but was not then present; in February two cases were reported, by the last of March the percentage on blood examination had risen to 20 per cent., and in April to 100 per cent.

It is to be noted that these Anophelines " did not greatly abound until after the laborers had been at this location for three weeks or more, and malaria made no headway until after two months."

From these observations Major Ashburn concludes, although for very different reasons than the usual ones of ability in length of flight, that " in ordinary sanitary practise, and not considering such exceptionally large and favorable breeding places, the control of all breeding within four hundred yards of towns, posts and houses serves to make them fairly comfortable and safe residences."

It is however the difference in reasons that makes Major Ashburn's conclusions of especial value, and the whole of Major Ashburn's paper is well worth study. It throws an absolutely new light on the subject, gives a valid reason for the acknowledged limit of four hundred yards as the usual flight of Anopheles, and clears up some points in mosquito control that have hitherto been obscure and bewildering.

C. S. LUDLOW

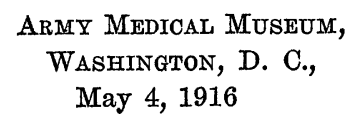

\section{SPECIAL ARTICLES}

THE ORIGIN BY MUTATION OF THE ENDEMIC PLANTS OF CEYLON

IN a recent paper Dr. J. O. Willis has made a statistical study of the flora of Ceylon in order to show that the indigenous species of this island must have been developed by muta-

3 Ashburn, P. M., "Elements of Military Hygiene,", 2 d ed. (1915). tion and without any kind of advantageous response to local conditions. ${ }^{1}$

It is obvious that the mutation theory wants in the first place a study of those facts which may throw a direct light on the evolution of wild species and that only relatively young forms have a sufficient chance of still living under the same or almost the same conditions, under which they originated. The material, afforded by the flora of Ceylon, is exceptionally rich in this respect and thoroughly well prepared by numerous investigators and especially in the great "Flora of Ceylon" by Trimen and Hooker.

Ceylon is a comparatively small island (25,000 sq. miles) and has a flora of 2,809 species of Angiosperms, of which 809 are endemic to the island.

Moreover of the 1,027 genera to which those species belong, 23 are confined to Ceylon, and among the 149 families, this is the case with six. Among the endemic genera 17 are represented by one species only, four by 2-3 and only two by a large number. These latter are Doona with 11 and Stemonoporus with 15 species, almost all of which are very rare forms, but distinguished from one another by characters of full specific rank. They give the impression that they may have been formed by what Standfuss has called explosive methods, a number of new species being produced almost at the same time.

As a rule, the endemic species are rare or very rare. More than a hundred of them are confined to one mountain top or to some very small area in the mountains.

Many of these occur as a very few individuals, say a dozen or little more, and the places where they can thrive are so small that it is obvious that they can never have been much more numerous. They must have evolved on the spot where they are found. Notwithstanding this, they are well-marked Linnean species and accepted as such by Trimen and Hooker. Not rarely their distinguishing characters are relatively large.

1 J. C. Willis, "The Endemic Flora of Ceylon, with Reference to Geographical Distribution and Evolution in General," Phil. Trans. Roy. Soc. London, Series B, Vol. 206, pp. 307-342. 